\title{
Fasiyal asimetrinin ortodontik-cerrahi tedavisi: Vaka raporu*
}

\author{
Neslihan Ebru Şenışık ${ }^{\alpha}$, Selin Öğreten Tunçay ${ }^{\alpha}$, Yavuz Fındık ${ }^{\beta}$, \\ Asım Aydın ${ }^{\gamma}$, Timuçin Baykul $^{\beta}$ \\ Başvuru Tarihi: 04 Nisan 2017 \\ Yayına Kabul Tarihi: 09 Mayıs 2017
}

Selcuk Dent J, 2017; 4: 94-100 (Doi: 10.15311/selcukdentj.303962)

\begin{abstract}
Öz
Fasiyal asimetrinin ortodontik-cerrahi tedavisi: Vaka raporu

Fasiyal asimetri farklı etyolojik sebeplerden kaynaklanabilir. Yüz asimetrisi üst yüze nazaran alt yüzü daha fazla etkiler. Fasiyal asimetrinin estetik görünüm açısından kabul edilemez olduğu erişkin vakalarda tedavi sıklıkla ortodontik ve ortognatik cerrahi tedavi kombinasyonu ile yapılır. Hasta memnuniyeti sağlamak için tedavi sonrası elde edilecek sonuç ile hasta beklentisinin örtüştüğünden emin olunmalıdır. Bu vaka raporunda, 20 yaşında fasiyal asimetri şikâyeti ile kliniğimize başvuran bayan hastanın ortodonti ve ortognatik cerrahi kombinasyonu ile tedavisi sunulmaktadır. Kombinasyon tedavisi, cerrahi öncesi ortodontik tedavi, ortognatik cerrahi ve cerrahi sonrası ortodontik bitirme olarak 3 fazda gerçekleştirilmiştir. Tedavi, sabit ortodontik tedav ve tek çeneyi içine alan ortognatik cerrahi kombinasyonu ile yapılmıştır. Tedavi başında planlanan sonuçlara başarıyla ulaşılmış, vakaya hedeflenen fonksiyon ve yüz estetiği kazandırıımıştır.
\end{abstract}

\section{ANAHTAR KELIMELER}

Asimetri, ortognatik cerrahi, sagittal split ramus osteotomisi

İyi bir yüz estetiği sağlamak için iskeletsel ve dişsel orta hatların uyumlu olması önemlidir. ${ }^{1}$ Ancak sıklıkla göz ardı edilen ve tedavi gerektirmeyen hafif yüz asimetrisi normal hatta çekici yüze sahip bireylerde bile bulunabilir. Yüz bölgesinde, orta hat asimetrilerinin farklı bileşenleri ve gözlemcilerin bireysel özellikleri, orta hat asimetrisinin kabul edilebilirliğini etkileyebilir. ${ }^{2}$ Normal kabul edilen bir asimetri ile anormal olduğu düşünülen bir asimetri arasındaki fark, sıklıkla klinisyenin ve/veya bireyin kendine ait sağ-sol taraf arası denge-dengesizlik hissi ile belirlenir. $^{3}$

Yüz asimetrisi üst yüze nazaran alt yüzü daha fazla etkiler. ${ }^{4}$ Yüzün alt kısmı, orta ve üst kısmına nazaran hem miktar hem de sıklık olarak daha fazla deviye olur. Bunun sebebi mandibulanın büyüme

\begin{abstract}
Orthodontic-surgery treatment of facial asymmetry: A case report

Facial asymmetry can be caused by different etiological causes. The lower face can be affected by face asymmetry more than the upper face. In adult cases where facial asymmetry is unacceptable in terms of aesthetic appearance, treatment is often a combination of orthodontic and orthognatic surgery. In order to achieve patient satisfaction, patient expectations should be known. In this case report, a 20 -year-old female patient with a complaint of facial asymmetry is presented with a treatment in combination of orthodontic and orthognathic surgery. Combination therapy was performed in 3 phases as pre-surgical orthodontic treatment, orthognathic surgery, and post-surgical orthodontic treatment. The treatment was performed with a combination of fixed orthodontic treatment and lower jaw surgery. The planned outcomes were successfully achieved, and the function and facial aesthetics were improved.
\end{abstract}

\section{KEYWORDS}

Asymmetry, orthognathic surgery, sagittal split ramus osteotomy

potansiyelinin ve periyodunun daha fazla olması ile

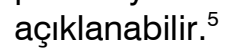

Fasiyal asimetri Sını I malokluzyonla beraber görülebilmesine rağmen, duruma daha çok Sınıf II ve Sınıf III malokluzyon eşlik eder. Fasiyal asimetri; (a) konjenital , (b) gelişimsel (büyüme döneminde ortaya çıkan) veya (c) hastalık veya yaralanma sonucu kazanıImış olabilir. ${ }^{6-8}$ Kondil asimetrisi, mandibula kaynaklı yüz asimetrilerinin en önemli sebebidir., ${ }^{9,11}$ Çene ucu daima kondilin kısa olan tarafına doğru kayar. ${ }^{12}$ İdiyopatik laterale deviye mandibulaya sebep olan durumlar 2 kategoride incelenebilir. ${ }^{13}$ illki mandibulanın yer değiştirmesine sebep olan kranial kaide ve gleniod fossa değişiklikleridir (musküler tortikollis, unilateral koronal kraniosinostozis, deformasyonel plagiosefali). ${ }^{14-17}$ Ikincisi ise mandibuler

\footnotetext{
* Çalışmada belirtilen vakanın ortodontik tedavi planlaması, bu yayının yazımı, çizimlerin, çakıştırmaların, tabloların hazırlanması Dr. Neslihan Ebru Şenışık tarafindan yapılmıştır. Vakanın ortodontik tedavisi Uzman Dt. Selin Öğreten Tunçay tarafından yürütülmüştür. Bu çalışmada sunulan vakanın cerrahi operasyonu Yrd.Doç.Dr. Yavuz Fındık, Prof. Dr. Asım Aydın ve Prof. Dr. Timuçin Baykul tarafından yapılmıştır.

${ }^{\alpha}$ Süleyman Demirel Üniversitesi Diş Hekimliği Fakültesi Ortodonti AD, Isparta

ß Süleyman Demirel Üniversitesi Diş Hekimliği Fakültesi Ağız Diş Çene Cerrahisi AD, Isparta

${ }^{v}$ Süleyman Demirel Üniversitesi Diş Hekimliği Fakültesi Plastik Rekonstrüktif ve Estetik Cerrahi AD, Isparta
} 
kondilin hiperplastik veya hipoplastik büyümegelişmesi ile sonuçlanan kondiller anomalilerdir (kondiller fraktür, kondiller hiperplazi, kondiller artrit, hemifasiyal mikrosomia) $)^{7,18-21}$

Gelişimsel tip fasiyal asimetri idiyopatiktir ancak sendromik değildir ve genel popülasyonda çok sık görülmez. Asimetri doğumda ya da çocukluk döneminde gözlenmemekle beraber, gençlik döneminde belirgin hale gelmektedir. Asimetri oluşmasında belirgin travma, yada tanısı konmuş bir hastalık yoktur. Durumun oluşmasında tek tarafı habitüel çiğneme (çiğnemenin olduğu tarafın aksi tarafında artmış iskeletsel gelişim olması sebebiyle) ${ }^{22}$ veya aynı tarafa yatarak uyuma gibi sebepler etken olabilir.

Fasiyal asimetriler, bireyin çiğneme ve konuşma fonksiyonunu, yüz estetiğini ve psikolojik durumunu etkileyebilir. Bu vaka raporunda mandibula kaynaklı fasiyal asimetri sebebiyle ortodontik tedavi - bilateral sagittal split ramus osteotomisi (SSRO) kombinasyonu ile tedavi edilen genç erişkin bayan hastanın tedavisi sunulmuştur.

\section{OLGU SUNUMU}

Tedavi için kliniğimize başvuran 20 yaşındaki bayan hastanın şikâyeti çenesinin sağa doğru kaymış olması ve tek taraflı çiğnemesiydi. Alınan anamnezde herhangi bir sistemik rahatsızlığının olmadığı belirlendi. Ağız dışı muayenede alt çene ucunun sağa doğru deviye olduğu ve hastanın konveks bir profile sahip olduğu belirlendi (Resim 1a-d). Gülümseme sırasında dişeti görünümü normaldi. Mental kas aktivitesi normaldi ve hastanın dudakları rahatça kapanıyordu. Açma ve kapama hareketleri sırasında temporomandibuler eklemde bir rahatsızlık saptanmadı. Ağız içi muayenede, tüm daimi dişlerin ağızda olduğu, sol tarafta Sınıf III kanin ve molar ilişki, sağ tarafta Sınıf II kanin ve Sınıf III molar ilişki ve çapraz kapanışın olduğu gözlendi. Maksiller dental orta hat, yüz orta hattına göre simetrik, mandibuler dental orta hat ise $4 \mathrm{~mm}$ sağda idi (Resim 1e-j). Overjet ve overbite $1 \mathrm{~mm}$ olarak ölçüldü. Lateral sefalometrik analizde maksilla ve mandibulanın sagittal yön konumlarının normal sınırlar içine olduğu, alt yüz yüksekliğinin artmış olduğu, mandibulanın geriye ve aşağıya doğru rotasyon yaptığı, Witts değerinin -5.7 olduğu, alt ve üst kesici dişlerin protrüziv olduğu belirlendi (Resim 2a-b, Tablo 1). Anteroposterior sefalometrik analizde ise mandibulanın sağa doğru deviye olduğu belirlendi. İskeletsel mandibuler asimetri $2.7 \mathrm{~mm}$ idi (Resim 2c-e). Laterognatisi olan hastanın esas şikayeti, yüz görünümündeki asimetri olduğundan sabit ortodontik tedavi ve ortognatik cerrahi kombinasyonu ile tedavi edilmesine karar verildi.

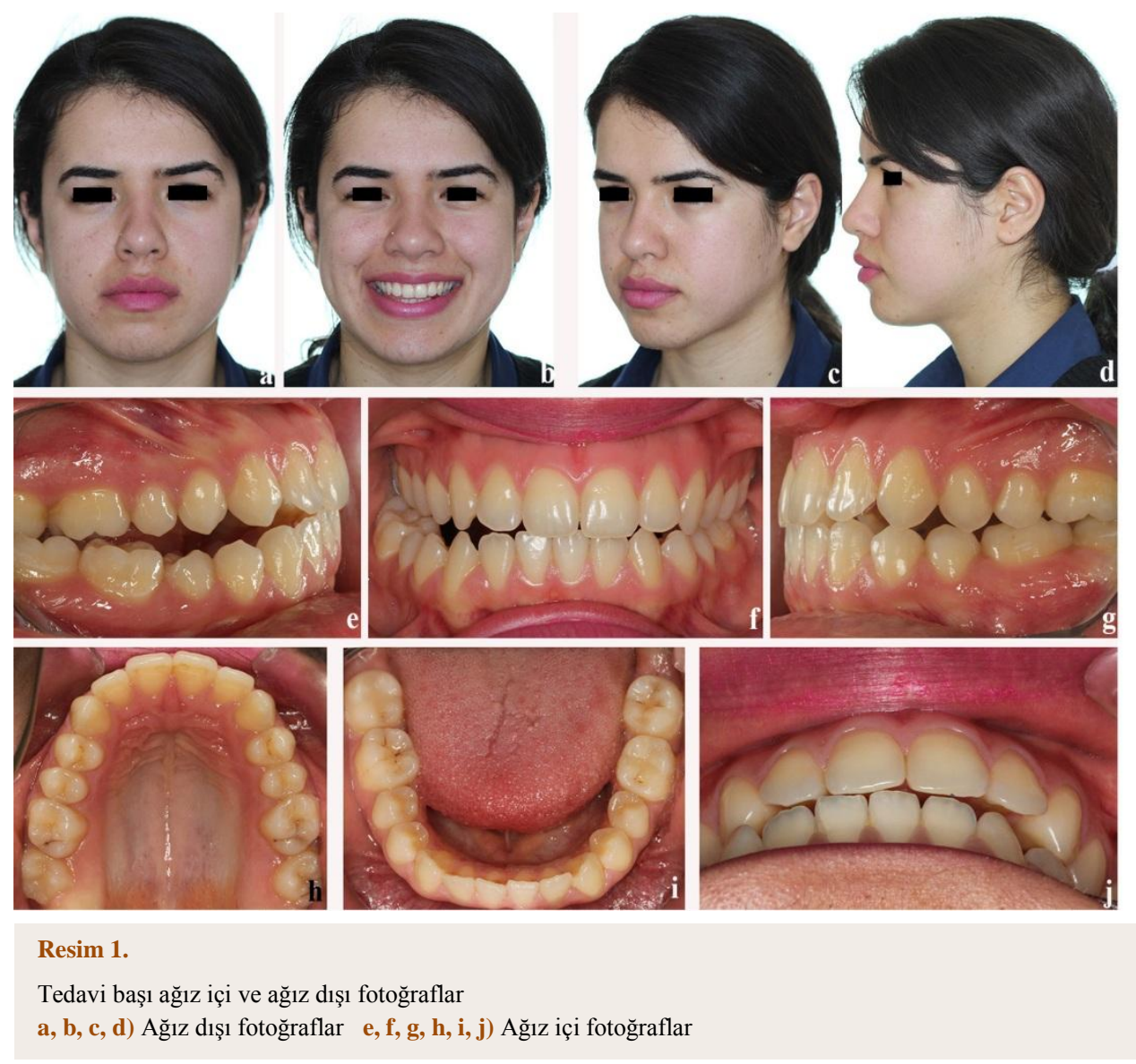



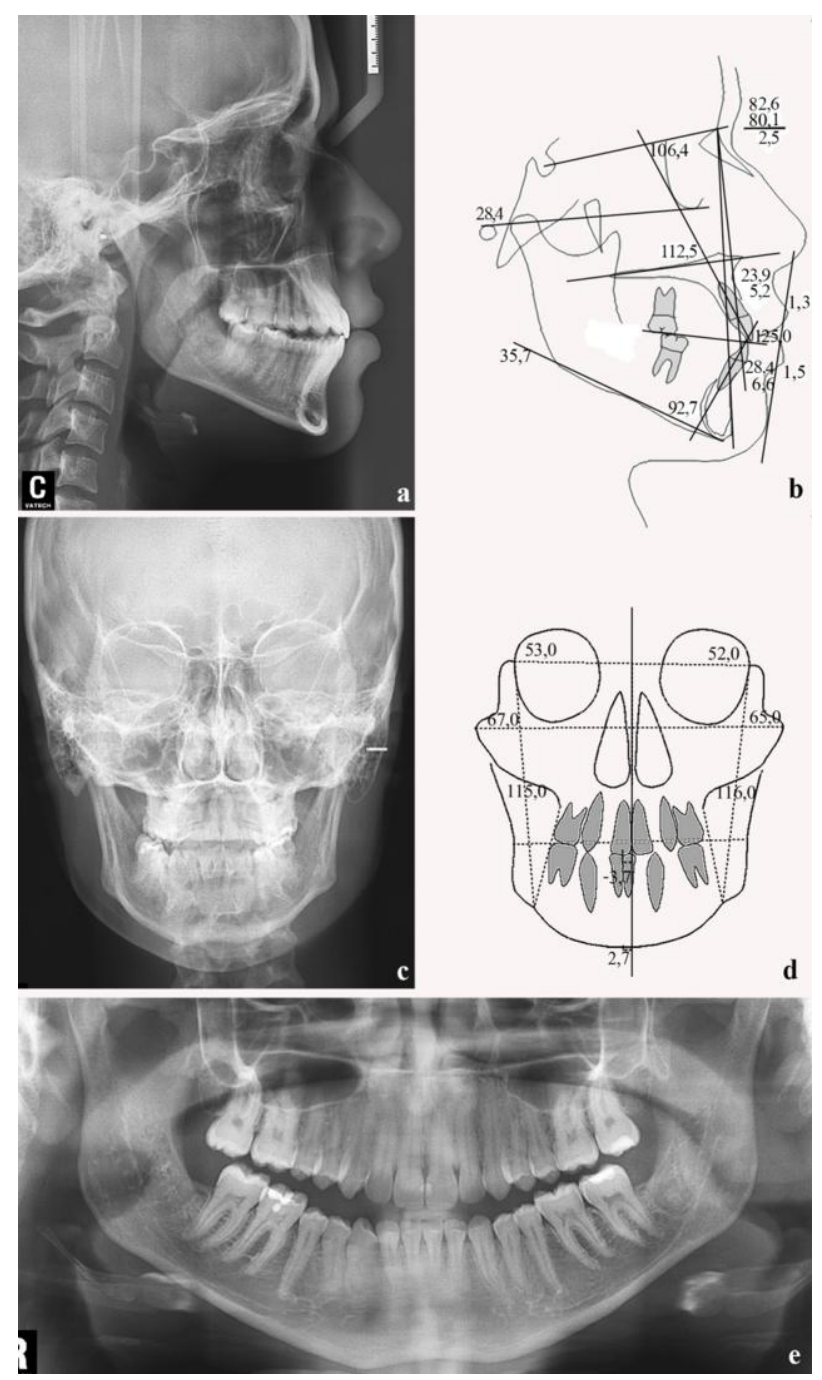

Resim 2.

Tedavi başı radyografiler ve analizleri

a, b) Lateral sefalometrik radyografi ve analizi

c, d) Posteroanterior radyografi ve analizi

e) Panoramik radyografi

Maksiller ve mandibuler dental arklara Mini Sprint, 0.018 inç slot, Roth braket (Forestadent, Pforzheim, Almanya) yerleştirildi. Sıralama seviyeleme sonrası maksiller dental arktaki çapraz kapanışın düzeltilmesi için geniş arklar kullanıldı. Sagittal yönde maksiller ve mandibuler keser diş pozisyonları düzeltildi. Operasyon öncesi periodik olarak alınan alt-üst çene alçı modelleri ile en iyi interküspitasyon sağlanıncaya kadar oklüzyon kontrol edildi. 0.017×0.022 inç paslanmaz çelik ark telleri ile tork eğimleri düzenlendi, $0.017 \times 0.022$ inç paslanmaz çelik arklarda braket aralarına ameliyat çengelleri yerleştirildi ve hasta cerrahi girişime hazır hale getirildi (Resim 3, Resim 4). Tedavi başlangıcında kemik dokunun iyileşmesi için 20 yaş dişleri çektirilmişti (Resim 4).
Tablo 1.

Tedavi başı, operasyon öncesi ve tedavi sonu dönemlerinde elde edilen lateral sefalometrik analiz verileri

\begin{tabular}{|c|c|c|c|}
\hline Ölçüm & $\begin{array}{c}\text { Tedavi } \\
\text { başı }\end{array}$ & $\begin{array}{l}\text { Operasyon } \\
\text { öncesi }\end{array}$ & $\begin{array}{c}\text { Tedavi } \\
\text { sonu }\end{array}$ \\
\hline $\operatorname{SNA}\left({ }^{\circ}\right)$ & 82,6 & 82,6 & 82,2 \\
\hline $\operatorname{SNB}\left({ }^{\circ}\right)$ & 80,1 & 80,2 & 79,3 \\
\hline $\mathrm{ANB}\left({ }^{\circ}\right)$ & 2,5 & 2,4 & 2,9 \\
\hline 1 - NA (mm) & 5,2 & 6 & 7,6 \\
\hline $1-\mathrm{NA}\left({ }^{\circ}\right)$ & 23,9 & 18,6 & 27,5 \\
\hline 1 - NB (mm) & 6,6 & 9,8 & 8 \\
\hline $1-\mathrm{NB}\left({ }^{\circ}\right)$ & 28,4 & 40 & 29,9 \\
\hline $1-1\left(^{\circ}\right)$ & 125 & 119,1 & 120,2 \\
\hline GoGn - SN( $\left(^{\circ}\right)$ & 35,7 & 37,4 & 34,5 \\
\hline Üst dudak - S(mm) & 1,3 & 0,7 & 1,9 \\
\hline Alt dudak - S(mm) & 1,5 & 1,1 & 2,9 \\
\hline IMPA $\left({ }^{\circ}\right)$ & 92,7 & 104,2 & 96,1 \\
\hline U1/PP $\left({ }^{\circ}\right)$ & 112,5 & 106,6 & 115,6 \\
\hline U1/SN $\left({ }^{\circ}\right)$ & 106,4 & 101,2 & 109,2 \\
\hline ANS-Me (mm) & 68,2 & 69,3 & 68,8 \\
\hline MP-FFH $\left(^{\circ}\right)$ & 28,4 & 29 & 26,2 \\
\hline Witt's $\left({ }^{\circ}\right)$ & $-5,7$ & $-6,2$ & $-2,4$ \\
\hline
\end{tabular}

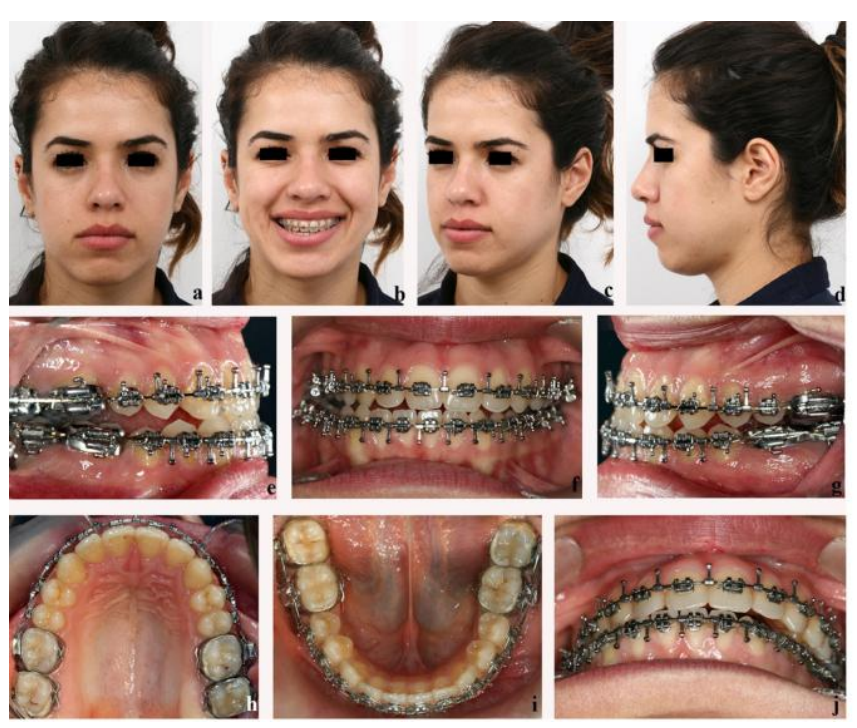

Resim 3.

Operasyon öncesi ağız içi ve ağız dışı fotoğraflar a, b, c, d) Ağız dışı fotoğraflar e, f, g, h, i, j) Ağız içi fotoğraflar 

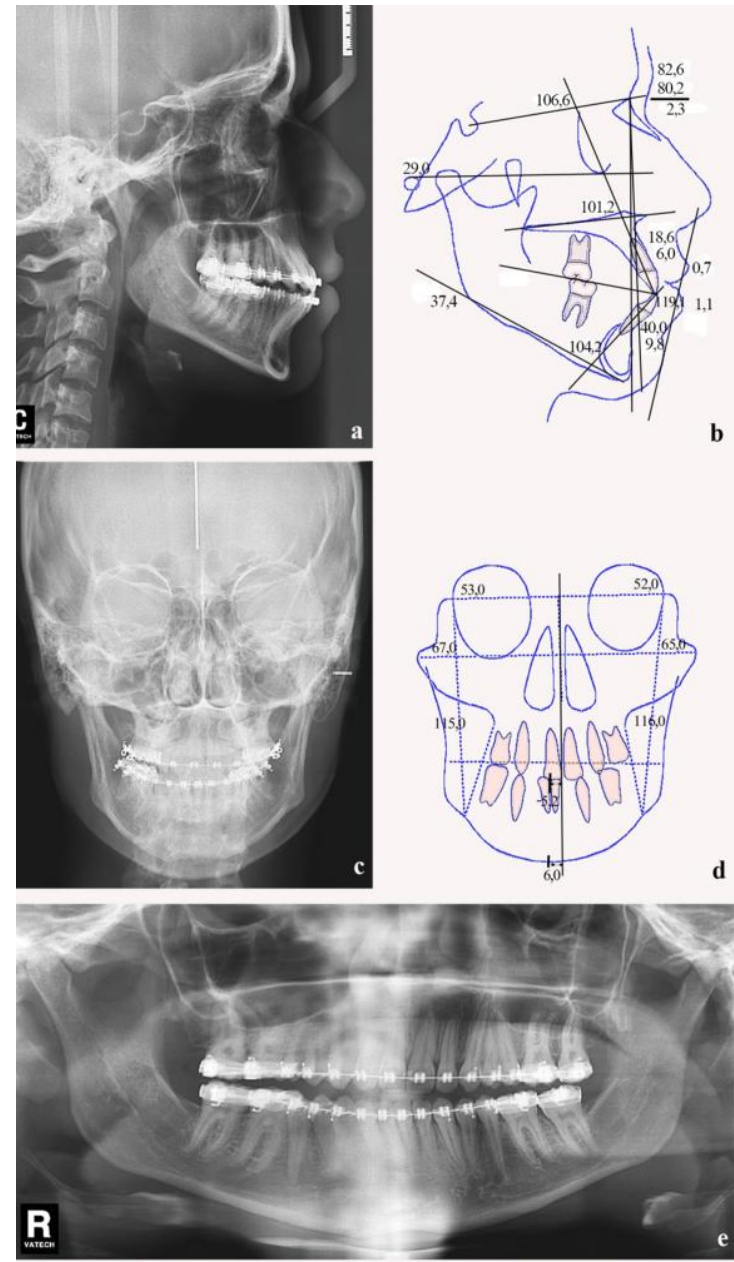

Resim 4.

Operasyon öncesi radyografiler ve analizleri a, b) Lateral sefalometrik radyografi ve analizi c, d) Posteroanterior radyografi ve analizi e) Panoramik radyografi

Maksillanın normal sınırlar içinde olması sebebiyle maksillaya herhangi bir cerrahi müdahale planlanmadı. Cerrahi müdahale olarak mandibuler bilateral SSRO, asimetrinin düzeltilmesi için mandibulanın sola rotasyonu, rotasyonu takiben mandibulanın geriye alınması ve okluzyonun sağlanması için saat yönünün tersine rotasyonu planlandı. Ameliyatın hemen öncesi planlama aşamasında hazırlanan splint, operasyon sırasında üst çeneye takıldı. Operasyon sonrası vaka splint ve intermaksiller elastikler ile takip edildi. Cerrahi girişimden 8 hafta sonra ortodontik tedaviye devam edildi ve operasyondan 12 ay sonra tedavi tümüyle bitirildi.

Sabit ortodontik tedavi ve alt çeneye uygulanan ortognatik cerrahi kombinasyonu ile tedavi edilen vakanın tedavisi 34 ay sürdü. Tedavi sonrası Sınıf I iskeletsel ve Sınıf I kanin ve molar dişsel ilişkinin sağlandığı, çapraz kapanışın ve yüz asimetrisinin ortadan kalktığı gözlendi. İdeal overjet ve overbite elde edildi. Hastaya estetik bir gülümseme kazandırıldı (Resim 5a-d). Maksiller, mandibuler iskeletsel ve dental orta hatlar çakıştıııdı ve simetri sağlandı (Resim 5e-j).
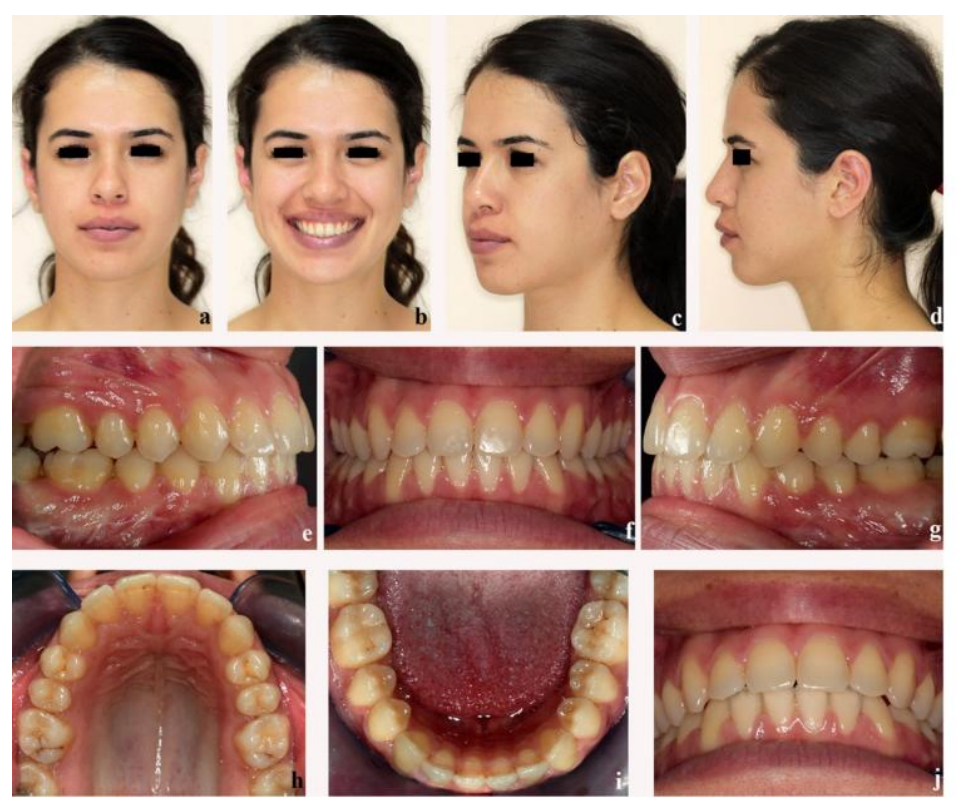

Resim 5.

Tedavi sonu ağız içi ve ağız dışı fotoğraflar

$a, b, c, d)$ Ağız dışı fotoğraflar e, f, g, h, i, j) Ağız içi fotoğraflar

Tedavi sonrası lateral sefalomerik analizlerin (Resim 6a-b, Tablo 1) ve Björk'ün total çakıştırmasının (Resim 7) sonuçlarına göre bu tedavi sonucunda mandibulanın hafif geriye hareket ettiği, saatin ters yönünde rotasyon yaptığı, yumuşak dokunun dengeli hale geldiği belirlendi. Best fit yöntemi ile posterior nazal spina orijin alınarak yapılan maksiller lokal çakıştırma, maksillada kesicilerin ortognatik cerrahi öncesi dikleştiğini, tedavi bitiminde ise ilk haline geri döndüğünü gösterdi. Björk'e göre özellikle anterior simfiz bölgesi dikkate alınarak yapılan mandibuler lokal çakıştırmada ise cerrahi öncesi keserlerin protrüze olduğu ve mandibulanın saat yönünde rotasyon yaptığı, mandibulanın öne hareket ettiği, cerrahi sonrasında ise mandibulanın saatin ters yönünde rotasyon yaptığı ve geri hareket ettiği izlendi. Alt molar dişteki dikleşme dikkat çekici idi (Resim 7). Tedavi bitiminde maksiller ve mandibuler keserler norm değerleri arasında idi. Anteroposterior sefalometrik analizde asimetrinin giderildiği, mandibulanın maksillaya ve kafa kaidesine göre normal ve simetrik konumlandığı izlendi (Resim 6c-d).

\section{TARTIŞMA}

Erişkin bireylerde şiddetli fasiyal asimetrinin olması durumunda fonksiyon, fonasyon ve yüz estetiğinin iyileştirilmesi, dengeli ve uyumlu dişsel ve iskeletsel ilişkinin sağlanması için ortognatik cerrahi gereklidir. ${ }^{23}$ Dentofasiyal deformiteler için cerrahi müdahale kararları, estetik 
problemin hastanın farkında olmasına, oklüzal deformitenin derecesine ve buna eşlik eden sagittal veya dikey çene anomalisine bağlıdır. ${ }^{24}$

Severt \& Proffit $^{4}$ ve Haraguchi ve ark. ${ }^{5}$ sagittal yönde Sınıf III iskeletsel ilişkiye sahip mandibuler deviasyonlu bireylerin \%85'inin mandibulasının sola deviye olduğunu bildirmişlerdir. Peck ve ark. ${ }^{25}$ ise bireylerde asimetri eğiliminin sağ tarafa doğru olduğunu belirtmiştir. Bu vaka raporunda sunulan posterior rotasyon vakasında özellikle güldüğünde mandibuladaki sağa deviasyon ve yumuşak dokuda gözlenen sağ yöndeki fasiyal asimetri dikkat çekicidir.
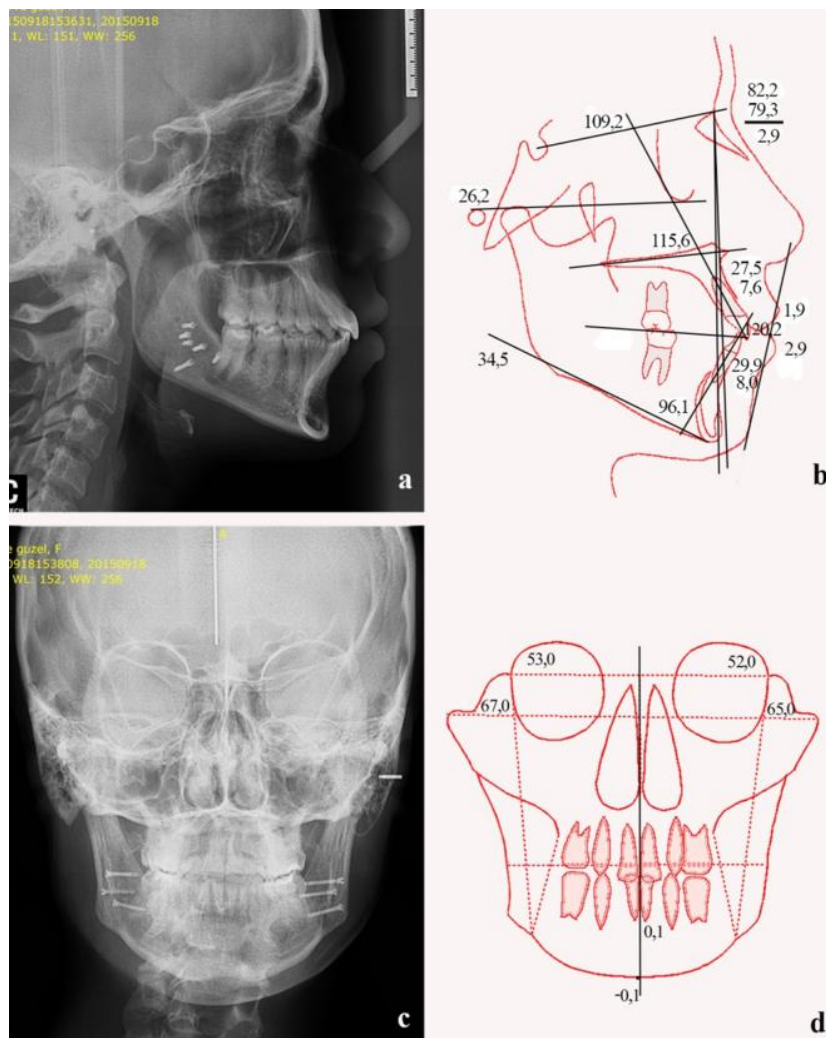

d

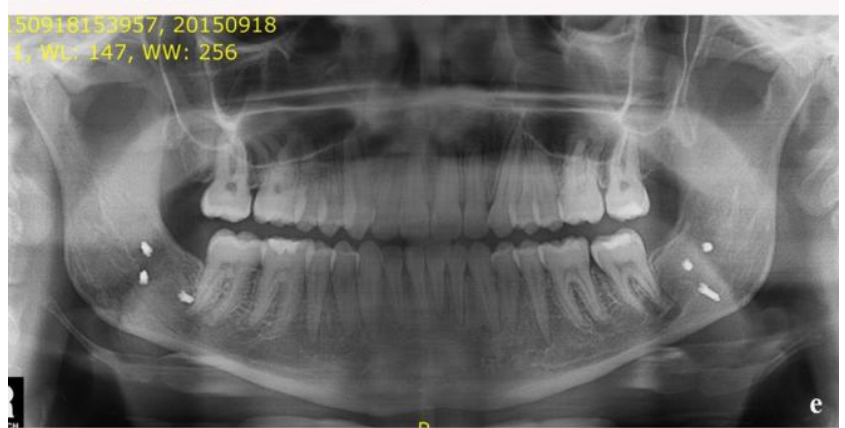

Resim 6.

Tedavi sonu radyografiler ve analizleri

a, b) Lateral sefalometrik radyografi ve analizi

c, d) Posteroanterior radyografi ve analizi

e) Panoramik radyografi

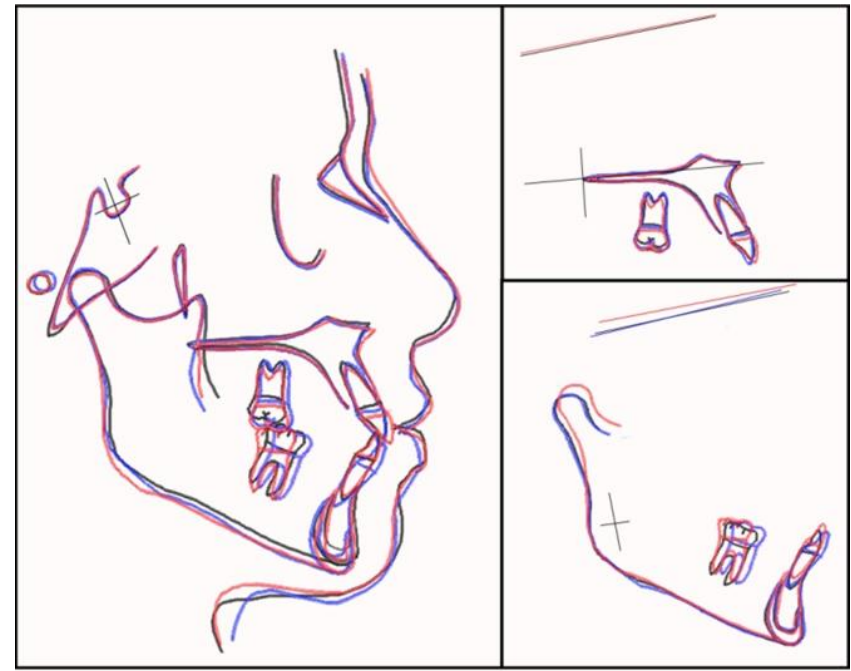

Resim 7.

Çakıştırmalar

a) Total çakıştırma

b) Maksiller lokal çakıştırma

c) Mandibuler lokal çakıştırma

Severt \& Profitt ${ }^{4}$, lateral deviasyon için asimetri-simetri kritik değerini $2 \mathrm{~mm}$ olarak belirtmiştir. Bu çalışmada sunulan vaka için belirlenen asimetri miktarı $2.7 \mathrm{~mm}$ dir.

Mandibulanın deviye olduğu vakalarda ağız içi muayenede görülen çapraz kapanışın maksillanın dar olmasından mı yoksa mandibulanın deviasyonundan mı kaynaklandığını belirlemek zorlayıcı olabilir. Sunulan vakada tedavi öncesi sağ tarafta çapraz kapanış gözlenmiştir. Tedavi sırasında alt üst çeneler arası transversal uyumsuzluk tedavi sonu stabiliteyi sağlamak amacıyla üst çenede arkların geniş çalışılması ve molar dişlere bukkal kök torku verilmesi ile düzeltilmiştir. ${ }^{26}$

Mandibuler asimetri sebebiyle tedavi edilen vakalarda maksiller yetersizliğin, açık kapanışın, maksiller okluzal eğim'in olduğu durumlarda cerrahi girişim her iki çeneyi de içerebilir. Ancak bu vaka raporunda sunulan vakada maksilla normal sınırlar içerisinde olduğundan ve üst oklüzyon düzleminde herhangi bir okluzal düzlem eğimi sapması (okluzal kant) görülmediğinden cerrahi girişim öncesi yapılan analizde operasyonun sadece mandibulaya yönelik yapılmasına karar verilmiştir. Ortognatik cerrahi tedavi planı kuşkusuz her bir bireyin kendi intiyaçları doğrultusunda yapılmaktadır.

Mandibüler laterognati yumuşak doku veya sert doku nedenli olabilmektedir. Yumuşak doku nedenli laterognatili hastalarda harhangi bir osteotomi yapmadan yumuşak dokuya yönelik yağ doku enjeksiyonları veya sentetik dolgu materyalleri ile asimetri düzeltilebilmektedir. Ancak sert doku 
kaynaklı bir laterognati mevcut ise bu hastalara sagital split ramus osteotomisi, vertikal ramus osteotomisi veya osseos genioplasti işlemleri yapılabilir. Asimetrinin şiddetine göre cerrahi sonrası distraksiyon osteogenezisi de tercih edilebilir. Şiddetli asimetri olan bireylerde SSRO ve gerekli ise genioplasti işlemi sıklıkla yapılmaktadır. Asimetrinin ciddiyetine göre bazen mandibuler alt kenar osteotomisi de yapılabilmektedir. Ciddi asimetrisi olmayan hastalarda çene ucuna yönelik genioplasti işlemi ile asimetri düzeltilebilmektedir.

SSRO, distal segmentin ön-arka hareketi sonrası iki kemik yüzeyinin genişçe temasta kalması, kemikleşmenin kolay olması ve nervus alveolaris inferior'a zarar verme riskinin diğer tekniklere göre daha az olması, operasyon sırasında oklüzyonun kontrolünün mümkün olması sebebiyle tercih edilir. ${ }^{27}$ $\mathrm{Bu}$ vaka raporunda tedavi amaciyla SSRO'nun seçilme nedeni, bu teknik ile mandibulanın öne arkaya hareketinin yanında sağa sola rotasyonununda yaptırılabilmesidir. Laterognatiye bağlı fonksiyon, estetik, temporomandibuler eklem problemleri, SSRO sonucu geriler. ${ }^{28,29}$

Bu vaka raporu sonuçları incelendiğinde, ortodontik ve cerrahi tedavi kombinasyonunun hedefleri olan maksiller ve mandibuler orta hatların çakıştırılması, yumuşak doku ve sert doku menton'un fasiyal orta hat ile çakıştırılmış olması, simetrik gülüş estetiği kazandırılması, ideal overjet, overbite, Sınıf I okluzal ilişkilerin sağlanması gibi hedeflere ulaşıldığı görülmektedir (Resim 5-7). Bu vaka raporunda mandibulanın deviasyonu sebebiyle asimetrik yüze sahip hastanın tedavisinde, tedavi başında planlanan sonuçlara başarıyla ulaşılmış fonksiyon ve estetik iyileştirilmiş, hastaya güzel bir gülümseme kazandırılmıştır.

Fasiyal estetiğin iskeletsel asimetri sonucu bozulduğu, büyüme gelişim potansiyelinin olmadığı vakalarda tedavi ortodontik-cerrahi tedavi kombinasyonu ile yapılır. Şiddetli olmayan mandibula kaynaklı laterognati vakalarında cerrahi teknik olarak SSRO, osteotomi sonrasında daha geniş bir hareket aralığı ve segmentlerin sabitlenmesi sırasında daha geniş kemik alanı sunması sebebiyle avantajlıdır. Hasta memnuniyeti sağlamak için yüz asimetrisine sahip hastaların tedavi sonrası beklentisi belirlenmeli ve tedavi sonrası elde edilecek sonuç ile hasta beklentisinin örtüştüğünden emin olunmalıdır. Aksi taktirde hastalar, tedavi sonucu ne kadar güzel olursa olsun sonuçtan tatmin olmayabilirler. 


\section{KAYNAKLAR}

1. Rebellato J. Asymmetric extractions used in the treatment of patients with asymmetries. Semin Orthod 1998; 4: 180-8.

2. Beyer JW, Lindauer SJ. Evaluation of dental midline position. Semin Orthod 1998; 4: 146-52.

3. Bishara SE, Burkey PS, Kharouf JG. Dental and facial asymmetries: a review. Angle Orthod 1994; 64: 89-98.

4. Severt TR, Proffit WR. The prevalence of facial asymmetry in the dentofacial deformities population at the University of North Carolina. Int J Adult Orthodon Orthognath Surg 1997; 12: 171-6.

5. Haraguchi S, Takada K, Yasuda Y. Facial asymmetry in subjects with skeletal Class III deformity. Angle Orthod 2002; 72: 28-35.

6. Hegtvedt AK. Diagnosis and management of facial asymmetry. Peterson LJ, Indressano AT, Marciani RD, Roser SM, editors. Oral and Maxillofacial Surgery. Philadelphia Lippincott; 1993. p.1400-1414.

7. Cohen MM Jr. Perspectives of craniofacial asymmetry. Part III. Common and/or well known causes of asymmetry. Int J Oral Maxillofac Surg 1995; 24: 12733.

8. Reyneke JP, Tsakiris $\mathrm{P}$, Kienle F. A simple classification for surgical planning of maxillomandibular asymmetry. $\mathrm{Br} \mathrm{J}$ Oral Maxillofac Surg 1997; 35: 349-51.

9. Schellhas KP, Piper MA, Omlie MR. Facial skeleton remodeling due to temporomandibular joint degeneration: an imaging study study of 100 patients. Am J Neuroradiol 1990; 11: 541-51.

10.Westesson PL, Tallents RH, Katzberg RW, Guay JA. Radiographic assessment of asymmetry of the mandible. Am J Neuroradiol 1994; 15: 991-9.

11. Yamashiro T, Okada T, Takada K. Case report: facial asymmetry and early condylar fracture. Angle Orthod 1998; 68: 85-90.

12. Koldaş T, Hayırlıoğlu T, Keskin C, Biren S. Surgical Treatment of Mandibular Laterognathism. Journal of Istanbul University Faculty of Dentistry 2013; 29 :89-93.

13. Kawamoto HK, Kim SS, Jarrahy R, Bradley JP. Differential diagnosis of the idiopathic laterally deviated mandible. Plast Reconstr Surg 2009; 124: 1599-609.

14.Lo LJ, Marsh JL, Pilgram TK, Vannier MW. Plagiocephaly: differential diagnosis based on endocranial morphology. Plast Reconstr Surg 1996; 97: 282-91.

15.Lo LJ, Marsh JL, Kane AA, Vannier MW. Orbital dysmorphology in unicoronal synostosis. Cleft Palate Craniofac J 1996; 33: 190-7.

16. Kane AA, Lo LJ, Vannier MW, Marsh JL. Mandibular dysmorphology in unicoronal synostosis and plagiocephaly without synostosis. Cleft Palate Craniofac J 1996; 33: 418-23.

17. Yu CC, Wong FH, Lo LJ, Chen YR. Craniofacial deformity in patients with uncorrected congenital muscular torticollis: an assessment from 3-dimensional CT imaging. Plast Reconstr Surg 2004;113:24-33.
18.Chen YR, Bendor-Samuel RL, Huang CS. Hemimandibular hyperplasia. Plast Reconstr Surg 1996;97:730-7.

19.Kane AA, Lo LJ, Christensen GE, Vannier MW, Marsh JL. Relationship between bone and muscles of mastication in hemifacial microsomia. Plast Reconstr Surg 1997;99:990-7.

20. Ortakoglu K, Akcam T, Sencimen M, Karakoc O, Ozyigit HA, Bengi O. Osteochondroma of the mandible causing severe facial asymmetry: a case report. Oral Surg Oral Med Oral Pathol Oral Radiol Endod 2007;103:e21-8.

21. Carlson ER. Pathologic facial asymmetries. Atlas Oral Maxillofac Surg Clin North Am 1996;4:19-35.

22. Shah SM, Joshi MR. An assessment of asymmetry in the normal craniofacial complex. Angle Orthod 1978;48:141-8.

23. Cheng LH, Roles D, Telfer MR. Orthognathic surgery: the patients' perspective. $\mathrm{Br} \mathrm{J}$ Oral Maxillofac Surg. 1998;36:261-3.

24.Ko EWC, Huang CS, Chen YR. Characteristics and corrective outcome of face asymmetry by orthognathic surgery. J Oral Maxillofac Surg 2009;67:2201-9.

25. Peck S, Peck L, Kataja M. Skeletal asymmetry in esthetically pleasing faces. Angle Orthod. $1991 ; 61: 43-8$.

26. Proffit WR, Turvey TA, Phillips C. The hierarchy of stability and predictability in orthognathic surgery with rigid fixation: an update and extension. Head Face Med 2007;30:3-21.

27.Öğütcen Toller M, Taşraya Yılmaz N, Özkan N, Uzun E. Bir Olgu Nedeniyle Ortognatik Cerrahi ile Düzeltilen Fasial Asimetrinin Üç Boyutlu Bilgisayarlı Tomografi Yöntemi ile İncelenmesi. Ondokuz Mayis Univ Dis Hekim Fak Derg 2001;6:20-3.

28. Epker BN. Modifications in the sagittal osteotomy of the mandible. J Oral Surg. 1977;35:157-9.

29.Rivera SM, Hatch JP, Dolce C, Bays RA, Van Sickels JE, Rugh JD. Patients' own reasons and patient perceived recommendations for orthognathic surgery. Am J Orthod Dentofacial Orthop 2000;118:134-41.

Yazışma Adresi:

Yrd.Doç.Dr. Neslihan Ebru ŞENIŞIK

Süleyman Demirel Üniversitesi

Diş Hekimliği Fakültesi

Ortodonti AD, Isparta

Tel : +902462118806

GSM : +90 5333757535

Faks : +902462370607

E-mail : nebuydas@yahoo.com 